\title{
Determinants of Metabolic Syndrome and 5-Year Cardiovascular Risk Estimates among HIV-Positive Individuals from an Indian Tertiary Care Hospital
}

\author{
Sneha Deepak Mallya $\mathbb{D D}^{1,2}$ Sravan Kumar Reddy $T \mathbb{D}^{3},{ }^{3}$ Asha Kamath ${ }^{1 D},{ }^{4}$ \\ Akhilesh Kumar Pandey $\mathbb{D}^{1}{ }^{1}$ and Kavitha Saravu $\mathbb{D}^{5,2}$ \\ ${ }^{1}$ Department of Community Medicine, Kasturba Medical College, Manipal Academy of Higher Education, Manipal, \\ Karnataka 576104, India \\ ${ }^{2}$ Manipal Centre for Infectious Diseases (MAC ID), Prasanna School of Public Health, Manipal Academy of Higher Education, \\ Manipal, Karnataka 576104, India \\ ${ }^{3}$ Cardiovascular Health Officer, World Health Organization, Warangal, Telangana 506001, India \\ ${ }^{4}$ Department of Data Sciences, Prasanna School of Public Health, Manipal Academy of Higher Education, Manipal, \\ Karnataka 576104, India \\ ${ }^{5}$ Department of Infectious Diseases, Kasturba Medical College, Manipal Academy of Higher Education, Manipal, \\ Karnataka 576104, India \\ Correspondence should be addressed to Sneha Deepak Mallya; sneha.kamath@manipal.edu
}

Received 16 March 2020; Revised 17 August 2020; Accepted 30 September 2020; Published 28 October 2020

Academic Editor: Glenda Gray

Copyright (C) 2020 Sneha Deepak Mallya et al. This is an open access article distributed under the Creative Commons Attribution License, which permits unrestricted use, distribution, and reproduction in any medium, provided the original work is properly cited.

\begin{abstract}
Longer survival due to use of antiretroviral therapy (ART) has made human immunodeficiency virus- (HIV-) infected individuals prone to chronic diseases such as diabetes, hypertension, and cardiovascular diseases (CVD). Metabolic syndrome (MS), a constellation of risk factors which increase chances of the cardiovascular disease and diabetes, can increase the morbidity and mortality among this population. Hence, the present study was conducted with the objectives of estimating the prevalence and determinants of MS among ART naïve and ART-treated patients and assess their 5-year CVD risk using the reduced version of Data Collection on Adverse Effects of Anti-HIV Drugs (D : A : D) risk prediction model (D : A : D (R)). This hospital-based crosssectional study included 182 adults aged $\geq 18$ years. MS was defined using the National Cholesterol Education Program-Adult Treatment Panel-3 (NCEP ATP-3) criteria. Univariate and multivariate logistic regressions were done to identify the factors associated with MS. Prevalence of MS was $40.1 \%$ (95\% confidence interval $(\mathrm{CI})=33.0 \%-47.2 \%)$. About $24.7 \%$ of the participants had at least a single criterion for MS. Age $>45$ years (adjusted odds ratio $(\mathrm{AOR})=2.3 ; 95 \% \mathrm{CI}=1.1-4.9, p<0.018$ ) and body mass index $(\mathrm{BMI})>23 \mathrm{~kg} / \mathrm{m}^{2}(\mathrm{AOR}=6.4 ; 95 \% \mathrm{CI}=3.1-13.1, p<0.001)$ were positively associated with MS, whereas daily consumption of high sugar items was inversely associated $(\mathrm{AOR}=0.2 ; 95 \% \mathrm{CI}=0.1-0.5, p<0.001)$. More than $50 \%$ of the participants were found to have moderate or high 5-year CVD risk. Observed prevalence of MS among HIV patients was higher than other studies done in India. Considering a sizeable number of participants to be having moderate to high CVD risk, culturally appropriate lifestyle interventions need to be planned.
\end{abstract}

\section{Introduction}

Human immunodeficiency virus (HIV) continues to be a major public health issue with 36.7 million people living with HIV globally and 53\% of them receiving ART [1]. With the widespread use of ART, the survival rates have greatly improved among HIV-infected individuals [2]. However, there have been reports of long-term ART-related increase in cardiovascular risk among HIV-positive patients [3]. Also, CVD has become an important cause of death among 
HIV patients [4]. A number of metabolic abnormalities have been detected in HIV patients including dyslipidemia and insulin resistance which can increase the CVD risk [5]. A complex interaction between the host's advancing age, virus, inflammatory process, and ART use has been described as the underlying mechanism for the increased CVD risk among HIV-infected patients [6].

A quarter of deaths due to noncommunicable diseases were attributed to CVDs in India in the year 2014 [7]. Metabolic syndrome is a constellation of risk factors which can increase an individual's risk of developing atherosclerotic cardiovascular disease (ASCVD) [8]. Hence, metabolic syndrome as an entity can greatly contribute to enhanced CVD burden. While there exist some studies addressing metabolic syndrome in $\mathrm{HIV}$-infected population among Indians, the estimates vary [9-11]; a few studies are devoid of data on key cardiovascular risk factors such as tobacco, alcohol, and physical activity. With clear lacunae of such studies from India, this study was planned to estimate the prevalence and identify the factors associated with metabolic syndrome. With widespread availability of ART under the National AIDS (Acquired Immunodeficiency Syndrome) Control Program (NACP) and also the private sector institutions in India, the impact of CVD complications among HIV-infected individuals may undermine the success of health benefits achieved through ART use. Early diagnosis and prevention of these conditions may help to reduce the morbidity and mortality associated with CVD complications.

\section{Materials and Methods}

A cross-sectional study was conducted among HIV-positive ART-naïve individuals and those receiving ART at a tertiary care teaching hospital in southern India during March-June 2017. The study included all the HIV-positive ART-treated and ART-naïve adult males and nonpregnant females aged $\geq 18$ years, who visited the hospital during the study period.

A clearance was obtained from the Institutional Ethics Committee of Kasturba Medical College and Kasturba Hospital, Manipal, before the commencement of the study (IEC 26/2017). A written informed consent was obtained from the participants. Details including sociodemographic characteristics and behavioral factors such as diet, tobacco, and alcohol consumption were collected using a structured questionnaire (Supplementary Appendix 1). An enquiry was made regarding frequency of consumption of high salt items (extra table salt, pickle, salted fish, salted nuts, salt in salad, and salted snacks), high sugar items (sweets, soft drinks, jam, cakes, honey, ice cream, and extra table sugar), high fat items (cakes, sweets, ice cream, ghee, dalda, butter, cream, chocolates, fried food items, cookies, red meat, and junk food items), fish, and fruits and vegetables. The frequency of consumption of various food items was classified as daily, 23 times per week, at least once a week, and rarely. Current user of tobacco or alcohol was defined as daily or occasional consumption during the current year, and past user was defined as one who has quit for more than a year. A person who used tobacco or alcohol either currently or in the past was considered to have "ever used" any substance. Physical activity was estimated using the International Physical Activity Questionnaire (IPAQ), and the participants were classified as inactive, minimally active, and health-enhancing physical activity (HEPA) [12]. The 5-year cardiovascular risk was estimated among individuals by a Data Collection on Adverse Effects of Anti-HIV Drugs [D:A :D (R)] risk prediction model using a web-based calculator (https:// www.chip.dk/Tools-Standards/Clinical-risk-scores). This tool is based on a reduced model and estimates the risk of an individual developing cardiovascular disease (CVD) within the next 5 years. The $\mathrm{D}: \mathrm{A}: \mathrm{D}(R)$ does not include ART as a parameter, and it requires the following information: gender, age, smoking status, diabetes (diagnosis or on antidiabetic treatment), family CVD history, systolic blood pressure (SBP), total cholesterol, high-density lipoprotein (HDL), and cluster of differentiation 4 (CD4) count. The composite CVD outcome includes myocardial infarction, stroke, invasive coronary artery procedure (including coronary artery by-pass or angioplasty and carotid artery endarterectomy), or death from coronary heart disease. This $\mathrm{D}: \mathrm{A}: \mathrm{D}(R)$ model is valid for $\mathrm{HIV}$-infected individuals aged 18-75 years. The 5-year risk of CVD was classified as low $(<1 \%)$, moderate (1 to $5 \%)$, high (5 to $10 \%)$, or very high $(>10 \%)$ [13].

Anthropometric measures such as weight $(\mathrm{kg})$, height $(\mathrm{cm})$, and waist circumference $(\mathrm{cm})$ were measured. Body mass index (BMI) was computed and classified based on Indian classification [14]. Two blood pressure (BP) readings were taken through a digital sphygmomanometer, in sitting position in the right arm, 10 minutes apart, and an average of two readings was considered. Hypertension was defined as SBP/DBP of $\geq 140 / 90$ for those aged $<60$ years and $\geq 150 / 90$ for individuals aged above 60 years [15]. Diabetes was defined as fasting plasma glucose (FPG) $\geq 126 \mathrm{mg} / \mathrm{dl}$ and or postprandial plasma glucose $\geq 200 \mathrm{mg} / \mathrm{dl}$ [16]. Hypothyroidism was defined as serum triiodothyronine level $<0.80 \mathrm{ng} / \mathrm{ml}$ or serum thyroxine level $<5.1 \mathrm{micrograms} / \mathrm{dl}$ and or serum thyroid-stimulating hormone level $>4.2$ microinternational units/ml [17]. National Cholesterol Education Program-Adult Treatment Panel (NCEP-ATP3) 2005 revision criteria were used to define MS which were as follows: abdominal obesity (waist circumference $\geq 90 \mathrm{~cm}$ for Asian men or $\geq 80 \mathrm{~cm}$ for Asian women), fasting triglycerides (TG) $\geq 150 \mathrm{mg} / \mathrm{dl}$ or drug treatment for elevated triglycerides, HDL cholesterol (HDL-C) $\leq 40 \mathrm{mg} / \mathrm{dl}$ for men or $\leq 50 \mathrm{mg} / \mathrm{dl}$ for women or on drug treatment for reduced HDL-C, systolic/diastolic blood pressure(SBP/DBP) $\geq 130$ / $85 \mathrm{mmHg}$ or receiving drug treatment, and FPG $\geq 100 \mathrm{mg} / \mathrm{dl}$ or drug treatment for elevated glucose [18]. Asian cutoffs for abdominal obesity were taken $[19,20]$. Participants having three or more of the above criteria were considered to have MS.

2.1. Statistical Analysis. The data were entered and analyzed using the Statistical Package for Social Sciences (SPSS) version 15. Continuous variables were summarized using mean (standard deviation (SD)) or median (interquartile range (IQR)), and categorical variables have been expressed 
as percentages. The chi-square test and independent-sample $t$-test were used to find out association between categorical and continuous variables, respectively. The Mann-Whitney test was used to compare mean DAD scores. Univariate and multivariate logistic regressions were done to identify the factors associated with MS and unadjusted and adjusted odds ratio (OR), respectively, with $95 \%$ confidence intervals (CI) have been reported. The variables which were significant in univariate analysis were included in the multivariate analysis. A $p$ value of $<0.05$ was considered to be statistically significant.

\section{Results}

The study included a total of 182 (123 ART-treated and 59 ART-naïve) participants who visited the outpatient facility of the department of medicine or hospitalized as an inpatient during the months of March to June 2017. The recruitment of study participants is shown in Figure 1.

As shown in Table 1, non-nucleoside reverse transcriptase inhibitor- (NNRTI-) based ART regimen was administered to $75.4 \%$ of the participants, while $24.6 \%$ were on protease inhibitor- (PI-) based regimen.

A quarter of the participants $(24.7 \%)$ had at least one criterion for MS, and $3.8 \%$ of the participants had all the five criteria for MS. The overall prevalence of MS among participants was observed to be $40.1 \%(95 \% \mathrm{CI}=33.0 \%-47.2 \%)$ with a higher prevalence among individuals on ART as compared to ART-naïve individuals (43.1\% vs $33.9 \%$ ). However, this difference was not statistically significant $(p=0.23)$. There was no difference in the prevalence of MS across the two genders (males $=40.4 \%$ vs females $=40.3 \%$, $p=0.96)$.

The most common abnormal MS component observed was low HDL (68.1\%), whilst the least common was BP $\geq 130 / 85$ or being on antihypertensives (28.6\%).

Distribution of the overall morbidities among the participants was diabetes (15.9\%), hypertension (20.3\%), and hypothyroidism (5.5\%). As shown in Table 2, the lipid abnormalities were higher in ART-naive individuals and the other three components of MS were present to a greater extent among individuals on ART. The above differences with respect to various criteria of metabolic syndrome were found to be statistically significant among ART-naïve and ART-treated patients except for elevated TG levels. Low HDL values in ART naive could be because of them being more sedentary compared to people on ART.

Females had higher prevalence of abdominal obesity ( $49.3 \%$ vs $27.8 \%, p=0.004)$ and low HDL $(79.1 \%$ vs $61.7 \%$, $p=0.015)$ as compared to males. Males displayed a higher frequency of elevated TG (48.7\% vs $46.3 \%, p=0.75)$, BP $(32.2 \%$ vs $22.4 \%, p=0.15)$, and fasting blood sugar $(53.9 \%$ vs $35.8 \%, p=0.018)$ against females.

Among the study participants, $63.2 \%$ were male. Univariate analysis to find out the association between MS and sociodemographic, disease-related, and lifestyle factors has been shown in Table 3. It was observed that age $>45$ years., $\mathrm{BMI}>23 \mathrm{~kg} / \mathrm{m}^{2}$, duration since HIV infection $>36$ months, being on ART $>36$ months, and family history of diabetes,

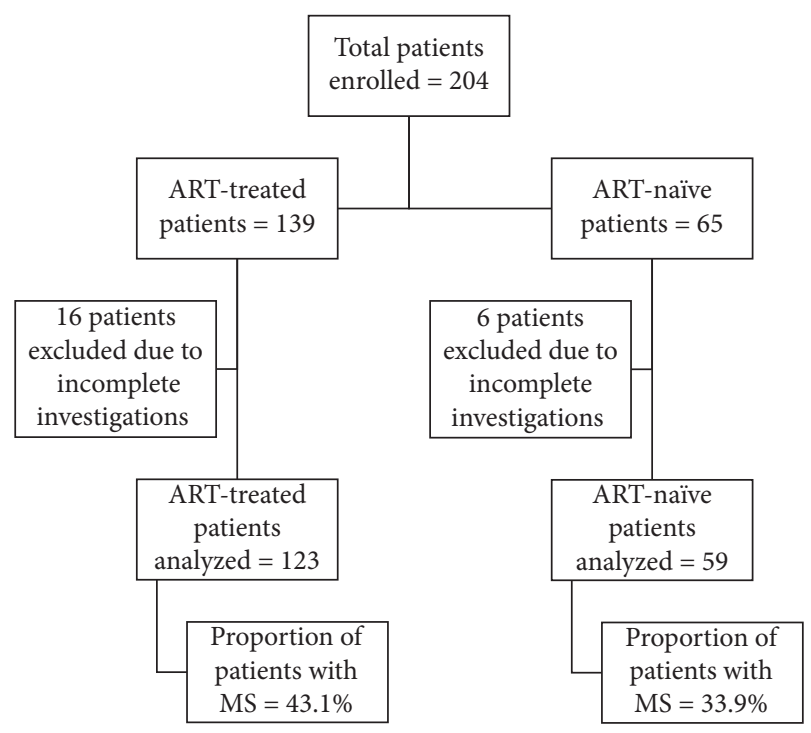

FIGURE 1: Flowchart showing recruitment of study participants.

TABLE 1: Details of the study participants according to class of ART received $(n=123)$.

\begin{tabular}{lcc}
\hline Drug class & Name of the drug & $n(\%)$ \\
\hline \multirow{2}{*}{ NNTRI } & Efavirenz & $82(66.7)$ \\
& Nevirapine & $13(10.6)$ \\
\hline \multirow{4}{*}{ NRTI } & Tenofovir & $97(78.9)$ \\
& Emtricitabine & $65(52.8)$ \\
& Lamivudine & $54(43.9)$ \\
& Zidovudine & $26(21.1)$ \\
\multirow{2}{*}{ PI } & Abacavir & $4(3.3)$ \\
& Atazanavir/ritonavir & $28(15.4)$ \\
& Darunavir/ritonavir & $2(1.6)$ \\
& Lopinavir/ritonavir & $1(0.8)$ \\
\hline
\end{tabular}

NNRTI, non-nucleoside reverse transcriptase inhibitors; NRTIs, nucleoside reverse transcriptase inhibitors; PI, protease inhibitor.

hypertension, and CVD were positively associated with MS. Consumption of high sugar and salt items on a daily basis or 23 times/week or once a week were inversely associated with MS.

The variables which were significant in univariate analysis were included in multivariate analysis. As shown in Table 4 , multivariate analysis found that age $>45$ years and BMI $>23 \mathrm{~kg} / \mathrm{m}^{2}$ were independently associated with MS, whereas daily high-sugar item consumption showed an inverse association.

Figure 2 shows the 5-year CVD risk among the study participants stratified by ART status. The overall median (IQR) D : A : D risk score for the study population was 1.4 $(0.6,2.8)$. Following was the distribution of 5-year CVD risk among all participants: low: 70 (38.7\%), moderate: 92 (50.8\%), high: $16(8.8 \%)$, and very high: 3 (1.7\%). A higher proportion of the participants belonged to moderate and high CVD risk groups in ART-treated category as compared to ART naive, and this difference was found to be statistically significant $(p<0.001)$. The median D:A:D score was significantly higher among males as compared to females ( $1.7 \mathrm{vs}$ $0.8, p<0.001)$. A significant difference was also noted 
TABLE 2: Various criteria for metabolic syndrome by ART status $(n=182)$.

\begin{tabular}{|c|c|c|c|}
\hline Criteria for MS & $\begin{array}{c}\text { On ART }(n=123) \\
n(\%)\end{array}$ & $\begin{array}{c}\text { ART naïve }(n=59) \\
n(\%)\end{array}$ & $p$ value \\
\hline Presence of abdominal obesity & $52(42.3)$ & $13(22.0)$ & 0.008 \\
\hline Elevated fasting TG or drug treatment for elevated TG & $56(45.5)$ & $31(52.5)$ & 0.37 \\
\hline Low HDL-C or on drug treatment for reduced HDL-C & $73(59.3)$ & $51(86.4)$ & $<0.001$ \\
\hline Elevated $\mathrm{SBP} / \mathrm{DBP} \geq 130 / 85 \mathrm{mmHg}$ or receiving drug treatment & $42(34.1)$ & $10(16.9)$ & 0.01 \\
\hline Elevated FPG or drug treatment for elevated glucose & $66(53.7)$ & $20(33.9)$ & 0.01 \\
\hline
\end{tabular}

TG, triglycerides; HDL-C, high-density lipoprotein cholesterol; SBP, systolic blood pressure; DBP, diastolic blood pressure; FPG, fasting plasma glucose.

TABLE 3: Factors associated with MS on univariate analysis $(n=182)$.

\begin{tabular}{|c|c|c|c|c|c|}
\hline Variable & Category & $\begin{array}{c}\text { MS present } \\
(n=73)\end{array}$ & $\begin{array}{c}\text { MS absent } \\
(n=109)\end{array}$ & OR with $95 \% \mathrm{CI}$ & $p$ value \\
\hline \multicolumn{6}{|l|}{ Background characteristics } \\
\hline \multirow{2}{*}{ Age in years } & $\leq 45$ & $23(31.5)$ & $56(51.4)$ & 1 & - \\
\hline & $>45$ & $50(68.5)$ & $53(48.6)$ & $2.2(1.2-4.2)$ & 0.009 \\
\hline \multirow{2}{*}{ Gender } & Male & $46(63.0)$ & $69(63.3)$ & $0.9(0.5-1.8)$ & 0.96 \\
\hline & Female & $27(37.0)$ & $40(36.7)$ & 1 & - \\
\hline \multirow{2}{*}{ Marital status } & Ever married & $71(97.3)$ & $98(89.9)$ & 1 & - \\
\hline & Single & $2(2.7)$ & $11(10.1)$ & $0.2(0.0-1.1)$ & 0.07 \\
\hline \multirow{2}{*}{ Education } & Up to 7 years of schooling & $19(26.0)$ & $30(27.5)$ & $0.9(0.4-1.8)$ & 0.82 \\
\hline & $>7$ years of schooling & $54(74.0)$ & $79(72.5)$ & 1 & - \\
\hline \multirow{2}{*}{ Occupation } & Employed & $44(60.3)$ & $78(71.6)$ & 1 & - \\
\hline & Homemaker/unemployed & $29(39.7)$ & $31(28.4)$ & $1.6(0.8-3.1)$ & 0.11 \\
\hline \multicolumn{2}{|c|}{$\begin{array}{ll}\text { Average monthly income } & \text { (Median (IQR)) } \\
\text { Disease- and treatment-related factors } & \end{array}$} & $4000(2500,7083)$ & $4000(2500,6667)$ & $1.0(1.0-1.0)$ & 0.55 \\
\hline \multirow{2}{*}{ Duration of HIV infection } & $\leq 36$ months & $32(43.8)$ & $66(60.6)$ & 1 & - \\
\hline & $>36$ months & $41(56.2)$ & $43(39.4)$ & $1.0(1.0-3.5)$ & 0.02 \\
\hline \multirow{2}{*}{ Recent CD4 count in cells $/ \mathrm{mm}^{3}$} & $\leq 500$ & $56(76.7)$ & $89(81.7)$ & $0.7(0.3-1.5)$ & 0.41 \\
\hline & $>500$ & $17(23.3)$ & $20(18.3)$ & 1 & - \\
\hline \multirow{2}{*}{ Treatment status } & On ART & $53(72.6)$ & $70(64.2)$ & $1.4(0.7-2.8)$ & 0.23 \\
\hline & ART naïve & $20(27.4)$ & $39(35.8)$ & 1 & - \\
\hline \multirow{2}{*}{ Duration of ART $(n=123)$} & $\leq 36$ months & $13(24.5)$ & $31(44.3)$ & 1 & - \\
\hline & $>36$ months & $40(75.5)$ & $39(55.7)$ & $2.4(1.1-5.3)$ & 0.02 \\
\hline \multirow{3}{*}{ ART regimen } & NNRTI based & $41(56.2)$ & $50(45.9)$ & $1.5(0.8-3.1)$ & 0.17 \\
\hline & PI based & $12(16.4)$ & $20(18.3)$ & $1.1(0.4-2.8)$ & 0.73 \\
\hline & ART naive & $20(27.4)$ & $39(35.8)$ & 1 & - \\
\hline \multicolumn{6}{|l|}{ Lifestyle factors } \\
\hline \multirow{2}{*}{ BMI } & Normal $\left(\leq 23 \mathrm{~kg} / \mathrm{m}^{2}\right)$ & $24(32.9)$ & $81(74.3)$ & 1 & - \\
\hline & $\begin{array}{l}\text { Overweight and obese } \\
\qquad\left(>23 \mathrm{~kg} / \mathrm{m}^{2}\right)\end{array}$ & $49(67.1)$ & $28(25.7)$ & $5.9(3.0-11.3)$ & $<0.001$ \\
\hline \multirow{3}{*}{ Physical activity } & Inactive & $35(32.1)$ & $22(30.1)$ & $0.9(0.2-3.7)$ & 0.93 \\
\hline & Minimally active & $68(62.4)$ & $47(64.4)$ & $1.0(0.2-3.8)$ & 0.95 \\
\hline & HEPA & $6(5.5)$ & $4(5.5)$ & 1 & - \\
\hline \multirow{2}{*}{ Tobacco consumption } & Ever & $11(15.1)$ & $21(19.3)$ & $0.7(0.3-1.6)$ & 0.46 \\
\hline & Never & $62(84.9)$ & $88(80.7)$ & 1 & - \\
\hline \multirow{2}{*}{ Alcohol consumption } & Ever & $19(26.0)$ & $30(27.5)$ & $0.9(0.4-1.8)$ & 0.82 \\
\hline & Never & $54(74.0)$ & $79(72.5)$ & 1 & - \\
\hline \multirow{3}{*}{ High-fat item consumption } & Daily & $8(11.0)$ & $23(21.1)$ & $0.4(0.1-1.1)$ & 0.09 \\
\hline & 2-3 times/week to once/week. & $39(53.4)$ & $53(48.6)$ & $0.9(0.4-1.8)$ & 0.83 \\
\hline & No/rarely & $26(35.6)$ & $33(30.3)$ & 1 & - \\
\hline \multirow{3}{*}{ High-sugar item consumption } & Daily & $24(32.9)$ & $63(57.8)$ & $0.2(0.09-0.4)$ & $<0.001$ \\
\hline & 2-3 times/week to once/week & $19(26.0)$ & $30(27.5)$ & $0.3(0.1-0.7)$ & 0.011 \\
\hline & No/rarely & $30(41.1)$ & $16(14.7)$ & 1 & - \\
\hline \multirow{3}{*}{ High-salt item consumption } & Daily & $29(39.7)$ & $56(51.4)$ & $0.3(0.1-0.7)$ & 0.01 \\
\hline & 2-3 times/week to once/week & $21(28.8)$ & $37(33.7)$ & $0.3(0.1-0.9)$ & 0.02 \\
\hline & No/rarely & $23(31.5)$ & $16(14.7)$ & 1 & - \\
\hline
\end{tabular}


TABLE 3: Continued.

\begin{tabular}{|c|c|c|c|c|c|}
\hline Variable & Category & $\begin{array}{l}\text { MS present } \\
(n=73)\end{array}$ & $\begin{array}{l}\text { MS absent } \\
(n=109)\end{array}$ & OR with 95\% CI & $p$ value \\
\hline \multirow{3}{*}{ Fish consumption } & Daily & $9(12.3)$ & $7(6.4)$ & 1 & - \\
\hline & 2-3 times/week to once/week & $33(45.2)$ & $36(33.0)$ & $0.7(0.2-2.1)$ & 0.54 \\
\hline & No/rarely & $31(42.5)$ & $66(60.6)$ & $0.3(0.1-1.0)$ & 0.06 \\
\hline \multirow{2}{*}{ Vegetable consumption } & Daily & $71(97.3)$ & $108(99.1)$ & 1 & - \\
\hline & 2-3 times/week & $2(2.7)$ & $1(0.9)$ & $3.0(0.2-34.1)$ & 0.36 \\
\hline \multirow{2}{*}{ Family history of hypertension } & Present & $25(34.2)$ & $20(18.3)$ & $2.3(1.6-4.5)$ & 0.01 \\
\hline & Absent & $48(65.8)$ & $89(81.7)$ & 1 & - \\
\hline \multirow{2}{*}{ Family history of DM } & Present & $26(35.6)$ & $27(24.8)$ & $1.6(0.8-3.2)$ & 0.11 \\
\hline & Absent & $47(64.4)$ & $82(75.2)$ & 1 & - \\
\hline \multirow{2}{*}{ Family history of CVD } & Present & $7(9.6)$ & $2(1.8)$ & $5.6(1.1-28.1)$ & 0.03 \\
\hline & Absent & $66(90.4)$ & $107(98.2)$ & 1 & - \\
\hline
\end{tabular}

HIV, human immunodeficiency virus; CD4, cluster of differentiation 4; ART, anti-retroviral therapy; NNRTI, non-nucleoside reverse transcriptase inhibitor; PI, protease inhibitor; BMI, body mass index; HEPA, health enhancing physical activity; CVD, cardiovascular disease;

TABLE 4: Factors associated with MS on multivariate analysis $(n=182)$.

\begin{tabular}{|c|c|c|c|}
\hline Variable & & OR with $95 \% \mathrm{CI}$ & $p$ value \\
\hline Age & $\begin{array}{l}\leq 45 \text { years } \\
>45 \text { years }\end{array}$ & $\begin{array}{c}1 \\
2.3(1.1-4.9) \\
\end{array}$ & 0.01 \\
\hline BMI & $\begin{array}{c}\text { Normal }\left(\leq 23 \mathrm{~kg} / \mathrm{m}^{2}\right) \\
\text { Overweight and obese }\left(>23 \mathrm{~kg} / \mathrm{m}^{2}\right)\end{array}$ & $\begin{array}{c}1 \\
6.4(3.1-13.1) \\
\end{array}$ & $<0.001$ \\
\hline High-sugar item consumption & $\begin{array}{l}\text { No/rarely } \\
\text { Daily }\end{array}$ & $\begin{array}{c}1 \\
0.2(0.1-0.5) \\
\end{array}$ & 0.001 \\
\hline
\end{tabular}

BMI, body mass index.

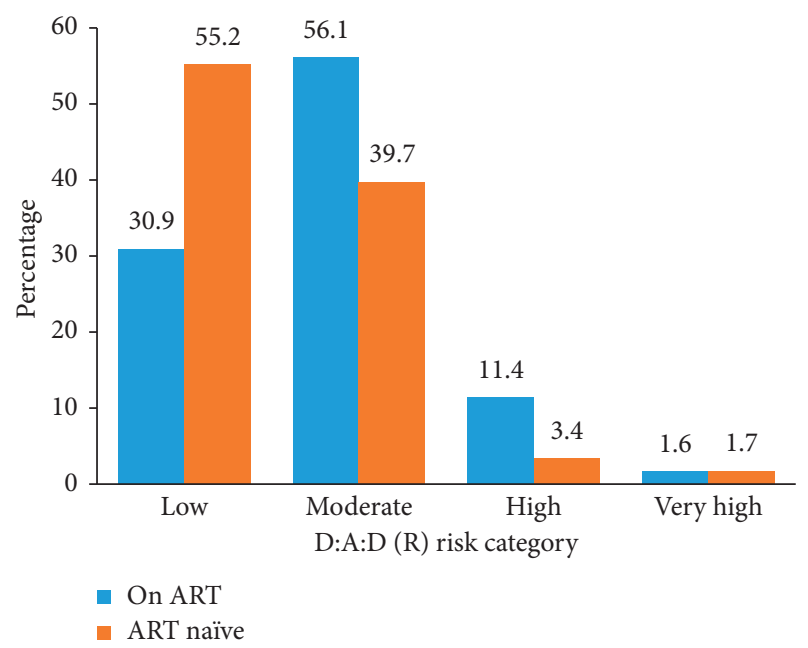

FIgURE 2: $\mathrm{D}: \mathrm{A}: \mathrm{D}(\mathrm{R})$ 5-year risk of CVD development by ART status $(n=181 *) * \mathrm{D}: \mathrm{A}: \mathrm{D}$ risk score could not be calculated for a participant as the age was above 80 years.

between median D : A : D scores of the two groups, i.e. ARTtreated vs ART-naïve individuals (1.7 vs $1.0, p<0.009)$.

\section{Discussion}

The prevalence of MS in the present study was $40.1 \%$. This is higher when compared to studies done elsewhere in India in which prevalence ranged from 19.8 to $26.6 \%$ [9-11].
Studies conducted outside India have reported a prevalence of MS from the lowest of $15.6 \%$ to the highest of $48.3 \%$ [21-29]. The prevalence of MS in the current HIV-infected participants is higher as compared to uninfected individuals in India in which the prevalence ranged from 18.4 to $30.9 \%$ [30, 31]. While most of the studies have used NCEPATP 3 criteria, few studies have used International Diabetes Federation (IDF) criteria for assessment of MS. Apart from the criteria used for assessment, this disparity may be attributed to the variation in prevalence of MS components among the patient population studied. Additionally, factors such as the type of study population selected (ART-naïve or ART-treated) and the type and duration of exposure to ART may be contributing factors for this observed difference.

The current study did not observe any statistically significant difference in MS prevalence between ART-treated and ART-naïve individuals. However, many studies have reported prevalence of MS to be higher among patients on ART as compared to their ART-naïve counterparts $[9,11,29]$. Results from a Nigerian study also reported that there was no increase in MS among the ART-treated group [27]. This may be due to the reason that only $0.6 \%$ of the study population received PI-based ART regimen, which are known to be associated with metabolic changes. The current study did not observe such association as PI-based regimen (ritonavir and atazanavir) was used among only 31 participants, and hence, did not have adequate power to detect this association. 
The current study found a quarter of the participants to be having at least one risk factor for MS. The proportion of participants with at least one abnormal MS component ranged from one-third to almost two-thirds of the study population among various other studies $[10,32]$. There was a wide variation in the type of predominant abnormal component among different studies. Similar to the findings of the present study, other studies from India and abroad $[10,11,22,25]$ have reported low HDL as the most common abnormal component of MS among HIV-positive individuals. While the present study found that BP $>130 / 85 \mathrm{~mm} \mathrm{Hg}$ or being on antihypertensive medication to be the least common abnormal component of MS, the study from Southeast Nigeria [27] observed it to be the most dominant component. Females in the study population had higher prevalence of low HDL cholesterol and abdominal obesity, and this may be a reflection of real differences pertinent to this population of coastal Karnataka and deserves further investigation.

The overall median 5-year CVD risk observed in the present study was higher than the study findings from Cameroon $(0.6 \%(0.3-1.3))$ in which $80 \%$ of participants were females [33]. As $63 \%$ of study population were males who are traditionally known to have higher CVD risk, the median score is higher in the present study. The study also found that median (IQR) 5-year CVD risk was higher among males in comparison to females $(1.4 \%(0.8-2.7)$ vs $0.5 \%(0.3-0.9), p<0.001)$, which is akin to findings of the present study [33]. While in the current study $38.7 \%$ of participants had low 5-year CVD risk, a study from Pune found that $63.5 \%$ of the study participants (median age $=40$ years) had low risk [34]. Another study from Brazil found that two-thirds of the HIV-infected participants (mean age $=36.8$ years) to be having low risk (74.2\%) [22]. Participants in the both the aforementioned studies were younger as compared to our study population which may be the reason for predominance of the low-risk category.

The present study found that age $>45$ years and high BMI to be positively associated with MS. Association between these traditional CVD risk factors and MS have been demonstrated in several studies among HIV-positive individuals $[23,24,28,35]$. While current study did not find any gender disparity in MS prevalence, Alvarez [24] and Berhane et al. [26] observed a female preponderance.

Studies by Pongthananikorn et al. from India [36] and Tiozzo et al. from United States of America [37] found a positive association between high sugar item consumption and MS; however, the present study found an inverse association between the two. This may be attributed to the fact that individuals with MS had higher frequency of diabetes and hypertension and, hence, may have reduced the consumption of sugar and salt, respectively.

Our study systematically dissected all components of metabolic syndrome in HIV-infected individuals in India. We further estimated their 5-year cardiovascular risk. Our study has highlighted the importance of higher BMI, a modifiable risk factor for MS, which could guide future preventive interventions. However, our study has certain limitations. As this study was carried out in a tertiary referral center, MS prevalence in the study setting may not be generalizable to the general $\mathrm{HIV}+$ population. The information collected on tobacco, alcohol consumption, and dietary factors was minimal, and this might have affected the results. Larger prospective studies are necessary to provide better understanding of the factors associated with MS.

\section{Conclusion}

Prevalence of MS is high among the HIV-infected study participants. Predictive factors for MS in this study were age and BMI, both being traditional risk factors. None of the HIV-related factors such as duration of infection, exposure to ART, and CD4 count were associated with presence of MS in this population. More than half of the study participants had moderate or high risk of development of CVD in the next five years. It is of utmost importance to develop specific interventions to prevent, diagnose, and treat MS among $\mathrm{HIV}$-infected patients to reduce their long-term morbidity and mortality. Early identification and instituting appropriate management will help to reduce future complications and mortality due to CVD.

\section{Data Availability}

The data used to support the findings of this study are available from the corresponding upon request.

\section{Ethical Approval}

Ethics committee approval was obtained from the Institutional Ethics Committee of Kasturba Medical College and Kasturba Hospital, Manipal (affiliated to Manipal Academy of Higher Education), India, prior to the commencement of the study.

\section{Conflicts of Interest}

The authors declare that they have no conflicts of interest.

\section{Acknowledgments}

The authors gratefully acknowledge the support received from the following clinical investigators from the Department of Medicine, Kasturba Medical College, Manipal, for the conduct of the study: Dr. Manjunath Hande, Dr. Sudha Vidyasagar, Dr. Shubha Seshadri, Dr. BA Shastry, Dr. Ram Bhat, Dr. Raviraj Acharya, Dr. Shivshankar, and Dr. Mukhyaprana Prabhu. The authors thank Ms. Shruthi Shetty, Research Assistant, who helped to collect the data for the study. The authors express their sincere gratitude to all the study participants. The authors would like to thank Manipal Centre for Infectious Diseases, Prasanna School of Public Health, Manipal Academy of Higher Education, Manipal (MAC ID/SGA/2016/010) for providing seed grant to carry out this study. 


\section{Supplementary Materials}

Supplementary Appendix 1: it consists of study tool with details pertaining to sociodemographic characteristics, disease-related information, behavioral factors such as diet, tobacco, and alcohol consumption, physical examination, and biochemical investigations. (Supplementary Materials)

\section{References}

[1] Number of people living with HIV and the number of HIV infected individuals receiving antiretroviral therapy. 2018: http://www.who.int/hiv/data/en/.

[2] Antiretroviral Therapy Cohort Collaboration, "Life expectancy of individuals on combination antiretroviral therapy in high-income countries: a collaborative analysis of 14 cohort studies," Lancet, vol. 372, pp. 293-299, 2008.

[3] F. Islam, J. Wu, J. Jansson, and D. Wilson, "Relative risk of cardiovascular disease among people living with HIV: a systematic review and meta-analysis," HIV Medicine, vol. 13, no. 8, pp. 453-468, 2012.

[4] N. Lohse, A.-B. E. Hansen, G. Pedersen et al., "Survival of persons with and without HIV infection in Denmark, 19952005," Annals of Internal Medicine, vol. 146, no. 2, pp. 87-95, Article ID 17227932, 2007.

[5] S. Grinspoon, and A. Carr, "Cardiovascular risk and body-fat abnormalities in HIV-infected adults," New England Journal of Medicine, vol. 352, no. 1, pp. 48-62, Article ID 15635112, 2005.

[6] J. N. Kiage, D. C. Heimburger, C. K. Nyirenda et al., "Cardiometabolic risk factors among HIV patients on antiretroviral therapy," Lipids in Health and Disease, vol. 12, no. 1, p. 50, 2013.

[7] Burden of non-communicable diseases in India, 2017, http://www.searo.who.int/india/topics/noncommunicable_ diseases/ncd_country_profile_2014.pdf?ua=1.

[8] National Cholesterol Education Program (NCEP), "Expert panel on detection, evaluation, and treatment of high blood cholesterol in adults (adult treatment panel III) third report of the national cholesterol education Program (NCEP) expert panel on detection, evaluation, and treatment of high blood cholesterol in adults (adult treatment panel III) final report," Circulation, vol. 106, pp. 3143-3421, 2002.

[9] D. P. Theengh, P. Yadav, A. K. Jain, and P. Nandy, "Assessment of metabolic syndrome in HIV-infected individuals," Indian Journal of Sexually Transmitted Diseases and AIDS, vol. 38, no. 2, pp. 152-156, 2017.

[10] S. Bajaj, A. Bhargava, and S. Tyagi, "Metabolic syndrome in human immunodeficiency virus positive patients," Indian Journal of Endocrinology and Metabolism, vol. 17, no. 1, pp. 117-120, 2013.

[11] J. Idiculla, G. D. D’Souza, G. D. Ravindran, G. Singh, and S. Furruqh, "Diabetes mellitus, insulin resistance, and metabolic syndrome in HIV-positive patients in South India," International Journal of General Medicine, vol. 4, pp. 73-78, 2011.

[12] International physical activity questionnaire, 2002, http:// people.umass.edu/be640/yr2004/resources/Internat-physicalactivity-worksheet.pdf

[13] N. Friis-Møller, L. Ryom, C. Smith et al., "An updated prediction model of the global risk of cardiovascular disease in HIV-positive persons: the Data-collection on Adverse Effects of Anti-HIV Drugs (D:A:D) study," European Journal of Preventive Cardiology, vol. 23, no. 2, pp. 214-223, 2016.
[14] A. Misra, P. Chowbey, B. M. Makkar et al., "Consensus statement for diagnosis of obesity, abdominal obesity and the metabolic syndrome for Asian Indians and recommendations for physical activity, medical and surgical management," Article ID 19582986, 2017.

[15] C. Armstrong, "JNC8 guidelines for the management of hypertension in adults," American Family Physician, vol. 90, no. 7, pp. 503-504, 2014.

[16] "Diagnosis and classification of diabetes mellitus," Diabetes Care, vol. 37, pp. S81-S90, 2014.

[17] Laboratory support for the diagnosis and monitoring of thyroid disease, 2016, http://www.nacb.org/lmpg/thyroid_ LMPG_PDF-stm.html.

[18] S. M. Grundy, J. I. Cleeman, S. R. Daniels et al., "Diagnosis and management of the metabolic syndrome," Circulation, vol. 112, no. 17, pp. 2735-2752, 2005.

[19] World Health Organization, "Waist circumference and waisthip ratio. report of who expert consultation," 2008, http:// apps.who.int/iris/bitstream/10665/44583/1/9789241501491_ eng.pdf.

[20] P. Z. Zimmet, and K. G. M. M. Alberti, "Introduction: globalization and the non-communicable disease epidemic," Obesity, vol. 14, no. 1, pp. 1-3, 2006.

[21] H. A. Mbunkah, H. D. Meriki, A. T. Kukwah, O. Nfor, and T. Nkuo-Akenji, "Prevalence of metabolic syndrome in human immunodeficiency virus - infected patients from the South- West region of Cameroon, using the adult treatment panel III criteria," Diabetology \& Metabolic Syndrome, vol. 6, no. 1, p. 92, 2014.

[22] H. Dohou, D. Shm, H. L. Codjo et al., "Prevalence and factors associated with metabolic syndrome in people living with HIV in parakou in 2016," Journal of Lipid and Atherosclerosis, vol. 1, no. 1, p. 1005, 2017.

[23] J. A. Leal, M. A. Fausto, and M. Carnetro, "Anthropometric risk factors for metabolic syndrome in HIV patients," Medical Express (Sao Paulo, Online), vol. 3, no. 4, Article ID M160405, 2016.

[24] C. Alvarez, R. Salazar, J. Galindez et al., "Metabolic syndrome in HIV-infected patients receiving antiretroviral therapy in Latin America," The Brazilian Journal of Infectious Diseases, vol. 14, no. 3, pp. 256-263, 2010.

[25] M. W. Nery, C. M. Martelli, E. A. Silveira et al., "Cardiovascular risk assessment: a comparison of the Framingham, PROCAM, and DAD equations in HIV-infected persons," Scientific World Journal, vol. 2013, Article ID 969281, 9 pages, 2013.

[26] T. Berhane, A. Yami, F. Alemseged et al., "Prevalence of lipodystrophy and metabolic syndrome among HIV positive individuals on HighlyActive Anti-Retroviral treatment in Jimma, South West Ethiopia," Pan African Medical Journal, vol. 13, no. 1, p. 43, 2012.

[27] K. Uwanuruochi, V. Uwanuruochi, F. Michael et al., "Assessment of Metabolic syndrome among adult human immunodeficiency virus/acquired immunodeficiency syndrome patients in a tertiary health facility in Southeast Nigeria," Journal of HIV and Human Reproduction, vol. 3, no. 2, pp. 41-46, 2015.

[28] M. F. Villamar, A. C. Albuja, and N. I. C. Salas, "Metabolic syndrome among HIV infected outpatients from a hospital in Quiti, Ecuador: a cross sectional study," Revista Panamericana de Infectología, vol. 13, no. 2, pp. 12-18, 2011.

[29] C. Obirikorang, L. Quaye, J. Osei-Yeboah, E. Odame, and I. Asare, "Prevalence of metabolic syndrome among HIV-infected patients 
in Ghana: a cross-sectional study," Nigerian Medical Journal, vol. 57, no. 2, pp. 86-90, 2016.

[30] M. Deepa, S. Farooq, M. Datta, R. Deepa, and V. Mohan, "Prevalence of metabolic syndrome using WHO, ATPIII and IDF definitions in Asian Indians: the Chennai urban rural epidemiology study (CURES-34)," Diabetes/Metabolism Research and Reviews, vol. 23, no. 2, pp. 127-134, 2007.

[31] R. Gupta, P. C. Deedwania, A. Gupta, S. Rastogi, R. B. Panwar, and K. Kothari, "Prevalence of metabolic syndrome in an Indian urban population," International Journal of Cardiology, vol. 97, no. 2, pp. 257-261, 2004.

[32] C. Jericó, H. Knobel, M. Montero et al., "Metabolic syndrome among HIV-infected patients: prevalence, characteristics, and related factors," Diabetes Care, vol. 28, no. 1, pp. 132-137, 2005.

[33] S. R. Noumegni, J. J. Bigna, V. J. A.M. E. Nkegoum et al., "Relationship between estimated cardiovascular disease risk and insulin resistance in a black African population living with HIV: a cross-sectional study from Cameroon," $B M J$ Open, vol. 7, no. 8, Article ID e016835, 2017.

[34] I. P. Marbaniang, D. Kadam, R. Suman et al., "Cardiovascular risk in an HIV-infected population in India," Heart Asia, vol. 9, no. 2, pp. 1-6, Article ID e010893, 2017.

[35] S. Krishnan, J. T. Schouten, B. Atkinson et al., "Metabolic syndrome before and after initiation of antiretroviral therapy in treatment-naive HIV-infected individuals," JAIDS Journal of Acquired Immune Deficiency Syndromes, vol. 61, no. 3, pp. 381-389, 2012.

[36] S. Pongthananikorn, K. Jantarathaneewat, P. Somnikha, S. Jaturapullarp, and K. Meksawan, "Prevalence and risk factors of metabolic syndrome in HIV-infected patients receiving the highly active antiretroviral therapy," Topics in Clinical Nutrition, vol. 33, no. 1, pp. 41-49, 2018.

[37] E. Tiozzo, J. Konefal, S. Adwan et al., "A cross-sectional assessment of metabolic syndrome in HIV-infected people of low socio-economic status receiving antiretroviral therapy," Diabetology \& Metabolic Syndrome, vol. 7, p. 15, 2015. 